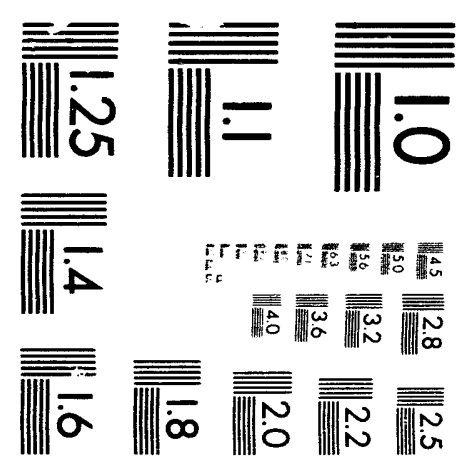



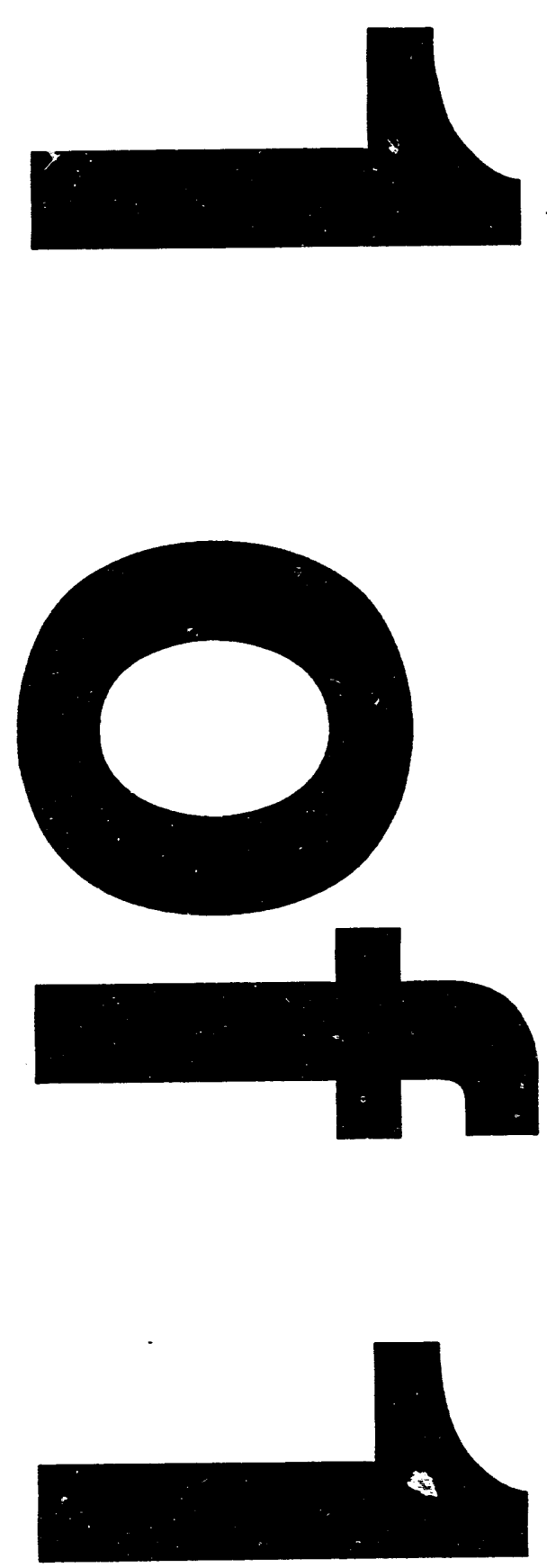


\title{
MOLTEN SALT OXIDATION OF MIXED WASTES: SEPARATION OF RADIOACTIVE MATERIALS AND RESOURCE CONSERVATION AND RECOVERY ACT \\ (RCRA) MATERIALS*
}

\author{
J. T. Bell \\ P. A. Haas \\ J. C. Rudolph \\ Chemical Technology Division \\ Oak Ridge National Laboratory \\ Post Office Box 2008 \\ Oak Ridge, Tennessee 37831-6223
}

For presentation at 8th Symposium on Separation Science and Technology for Energy Applications

October 24-28, 1993, Gatlinburg, TN

\section{DISCLAIMER}

\begin{abstract}
This report was prepared as an account of work sponsored by an agency of the United States Government. Neither the United States Government nor any agency thereof, nor any of their employees, makes any warranty, express or implied, or assumes any legal liability or responsibility for the accuracy, completeness, or usefulness of any information, apparatus, product, or process disclosed, or represents that its use would not infringe privately owned rights. Reference herein to any specific commercial priduct, process, or service by trade name, trademark, manufacturer, or otherwise does not necessarily constitute or imply its endorsement, recommendation, or favoring by the United States Government or any agency thereoi. The views and opinions of authors expressed herein do not necessarily state or reflect those of the United States Government or any agency thereof.
\end{abstract}

"Research sponsored by the Office of Facilities, Fuel Cycle, and Test Programs, U.S. Department of Energy under contract DE-AC05-84OR21400 with the Martin Marietta Energy Systems, Inc. 


\begin{abstract}
The Oak Ridge National Laboratory (ORNL) is participating in a program to apply a molten salt oxidation (MSO) process to treatment of mixed (radioactive and RCRA) wastes. The salt residues from the MSO treatment will require further separations or other processing to prepare them for final disposal. A bench-scale MSO apparatus is being installed at ORNL and will be operated on real Oak Ridge wastes. The treatment concepts to be tested and demonstrated on the salt residues from real wastes are described.
\end{abstract}

\title{
INTRODUCTION
}

The Oak Ridge National Laboratory (ORNL) is involved in a program to apply a molten salt oxidation (MSO) process to the treatment of mixed wastes at Oak Ridge and other Department of Energy (DOE) sites. Mixed wastes are defined as those wastes that contain both radioactive components. which are regulated by the atomic energy' legislation, and hazardous waste components, which are regulated under the Resource Conservation and Recovery Act (RCRA). A major part of our ORNL program involves the development of separation technologies that are necessary for the complete treatment of mixed wastes. The residues from the MSO treatment of the mixed wastes must be processed further to separate the radioactive components, to concentrate and recycle residues, or to convert the residues into forms acceptable for final disposal. This paper is a review of the MSO requirements for separation technologies, the information now available, and he concepts for our development studies.

\section{HISTORY OF MOLTEN SALT OXIDATION FOR WASTE TRI ATMEN', J}

Molten salt oxidation is not a new idea, having been initially introduce ${ }^{\prime} i$. the eark 1950 s by the Atomic Energy Commission (AEC) as a possible method of processing nucliar $f$ is Rockwell International carried out AEC-sponsored basic research with molten salts. One of li: irst applied uses for molten salt examined by Rockwell was as a scrubber for $\mathrm{SO}_{2}$ enulsilus from a coal gasitication plant. It was this application that gave Rockwell the concept of using molten salts, specifically carbonates, to treat hazardous waste. 
Rockwell has done tests on many hazardous compounds, such as polychlorinated biphenyls (PCBs), tributyl phosphate (TBP), and various chemical weapons (1,2). All tests showed excellent destruction efficiencies. Rockwell also performed test runs with simulated radioactive waste to show that radioactive particles would be retained in the salt (3). Even though these results showed effective treatment of wastes, incincration systems appeared to be more practical and more economical; most MSO research ended about 1982.

MSO has recently been brought back into the picture as a possible treatment for mixed waste. A recent test run performed at the Energy Technology Engineering Center (ETEC) on a hydrocarbon oil with low levels of ${ }^{1.37} \mathrm{Cs}$ and ${ }^{60} \mathrm{Co}$ showed promising results. The unit performing this test has been shipped to ORNL for further studies with DOE mixed wastes.

\section{MSO PROCESS DESCRIPTION}

The MSO process is fairly simple. as is illustrated in Figure 1. The salt is placed in either a metal or, more commonly, ceramic vessel. Generally, the height of the salt under static conditions should be roughly equal to the diameter of the vessel. The salt charge is preheated to the desired temperature $\left(650-1100^{\circ} \mathrm{C}\right.$ depending on the salt composition). The temperature must be high enough to reduce the salt's viscosity until it is similar to that of water. This allows for proper contact of air and feed with the salt bath. $\mathrm{A} \mathrm{Na}_{2} \mathrm{CO}_{3}$ melt requires temperatures $\geq 900^{\circ} \mathrm{C}$ (melting point of $851^{\circ} \mathrm{C}$ ) and probably a ceramic vessel. Metal alloy vessels might be used for salt mixtures with lower melting points.

The waste and air enter the salt either from the top of the vessel through an injection tube which ends about 2 in. from the base of the vessel. or they are fed through the vessel walls. The waste feed rate is limited by two conditions: (1) the exiting combustion gases should not have a superficial velocity $>2.5 \mathrm{lt} / \mathrm{s}$ or else there may be excessive entrainment in the off-gas stream, and (2) the heat produced from the waste must not raise the salt's temperature. The off-gas is passed through a prefilter system and then through an absolute filter before it is released to the atmosphere. The salt composition is controlled by addition of $\mathrm{Na}_{2} \mathrm{CO}_{3}$ and removal of spent salt. 


\section{MOLTEN SALT OXIDATION FOR TREATMENT OF MIXED WASTES}

For the purpose of describing the residues from treatment of mixed wastes, the MSO treatment involves simple chemical reactions. The waste, excess oxygen (or air), and the $\mathrm{Na}_{2} \mathrm{CO}_{3}$ are reacted to very nearly the chemical equilibrium at the molten salt temperature. The molten $\mathrm{Na}_{2} \mathrm{CO}_{3}$ reacts with acid gases to form sodium salts and $\mathrm{CO}_{2}$. The $\mathrm{Na}_{2} \mathrm{CO}_{3}$ is reported to act as a catalyst. The destruction efficiencies for toxic organics are as good (high) in molten salt at 900 to $1000^{\circ} \mathrm{C}$ as for simple incineration at temperatures over $2000^{\circ} \mathrm{C}$. Carbon and hydrogen are discharged as $\mathrm{CO}_{2}$ and $\mathrm{H}_{2} \mathrm{O}$.

One important characteristic of MSO as a waste treatment is the good retention of metals as oxides or salts in the salt residues. The entrained or condensed solids in the cooled off-gases are easily collected and discharged as a residue by bag filters. Acid gases react with $\mathrm{Na}_{2} \mathrm{CO}_{3}$ in the melt and are retained as the sodium salts. The MSO treatment results in efficient destruction of waste constituents to yield salt residues and off-gases without any aqueous scrubber residues.

The efficient collection of metallic salts and ash in the salt residues is both an advantage and limitation for MSO treatment of mixed wastes. The MSO treatment is not suitable for high contents of ash or noncombustible solids in the waste tieed: excessive amounts of the carbonate salt would be removed as residues in order to remove these solids. High concentrations of elements that form acid gases when reacted with oxygen ( $\mathrm{C}, \mathrm{F}, \mathrm{S}, \mathrm{P}$, etc.) convert large amounts of $\mathrm{Na}_{2} \mathrm{CO}_{3}$ to the corresponding sodium salts. The same amounts of sodium salts are formed in the scrubbers for incinerators. Whether the salt residues or the scrubber slurries are preferred residues is not obvious.

\section{FINAL WASTE FORM CONSIDERATIONS}

Waste treatment processes commonly generate residues. A primary objective of the overall treatment is to have all residues in a form acceptable for final disposal. For mixed wastes, the disposal of residues is very dependent on whether the original waste feed was considered hazardous as a listed or a characteristic waste under RCRA. The MSO treatment of mixed wastes generally gives high destructions of hazardous organic compounds and can be operated to eliminate the original characteristic hazards of ignitibility, corrosivity, and reactivity. The eight metallic elements that result in a characteristic toxicity hazard ( $\mathrm{Ar}, \mathrm{Ba}, \mathrm{Cd}, \mathrm{Cr}, \mathrm{Pb}, \mathrm{Hg}$, Se, and $\mathrm{Ag}$ ) would remain (as oxides, salts, or metals) in the residues. Overall, if the mixed waste were characteristically hazardous under RCRA. 
the MSO residues could probably be nonhazardous and could, thus, be disposed of subject to the DOE guidelines for radioactive wastes.

The final disposal of residues is much more difficult if the original waste is a listed hazard under RCRA. Any residues from treatment of a listed waste are considered to also be listed wastes. While the radioactive constituents may be changed chemically by waste treatments, they remain radioactive. There is no approved tinal disposal for these mixed waste residues. Separation and concentration of the radioactivity can give a much smaller volume of mixed waste and a larger residue for disposal as a hazardous waste solid. In theory, a residue can be "delisted" if the feed composition to a treatment and the performance of the treatment process can be standardized and demonstrated. This is very difficult and is not practical lor the varied compositions of most of the Oak Ridge DOE wastes.

In summary, the salt residues from MSO treatment of mixed wastes will require further separations or other processing to prepare them for linal disposal. The radioactivity should be concentrated to a minimum volume. For mixed wastes that are hazardous by characteristics, the residues can probably be RCRA nonhazardous and then can be disposed of as radioactive solid wastes. For listed mixed wastes, the best result currently possible is a minimum volume of mixed waste with no approved disposal option. The acceptable final solid forms are likely to incorporate the residues into glass, hydraulic cements, ceramics, organic matrices, or sulfur polymer materials. For MSO waste treatment residues, both the processing into such solid forms and the performance of such forms remain to be demonstrated.

\section{APPLICATIONS OF MSO TO OAK RIDGE MIXED WASTES}

The Chemical Development Section (CDS) of the Chemical Technology Division at ORNL has received a bench-scale MSO unit from ETEC. It has been brought to ORNL for the primary purpose of demonstrating the MSO treatment of real mixed wastes at the three Oak Ridge sites. Important information to be obtained from the MSO tests will be the destruction efficiency of organic compounds, the tinal location of radionuclides and RCRA materials, and the compatibility of materials. Operating procedures and test measurements will also be evaluated and modified as required.

The unit from ETEC is shown in Figure 2. In addition to what is depicted in the figure, it is worth noting that the off-gas is passed through $\mathrm{CO}_{2}, \mathrm{CO}, \mathrm{NO}_{x}, \mathrm{O}_{2}$, and hydrocarbon analyzers, 
which allow a comparison of the combustion products versus melt composition. The salt composition is analyzed from periodic samples of the melt. Unfortunately, a real-time measurement of salt composition has not yet been devised.

Prior to any tests in the MSO unit, the process will be modeled for that specific waste feed using readily available thermodynamic programs to predict system behavior. This will be done mostly as a safety feature to ensure compatibility of materials but will also provide a theoretical basis for comparison and analysis of results.

The variables that will be examined in the CDS study are waste composition (chemical and physical), salt composition. temperature of the salt bath, waste feed rate, and precent excess air. Waste composition is obviously the most critical variable, causing the others to be modified to give the best results (i.e., greatest organic destruction and retention of radioactive and RCRA materials in the melt). The general order of testing at ORNL will be as follows:

1. pure hydrocarbons.

2. halogenated hydrocarbons,

3. hydrocarbons containing nitrate groups.

4. halogenated hydrocarbons containing depleted uranium,

5. halogenated hydrocarbons containing tission products.

6. organic sludges.

7. activated carbon. and

8. organics containing beryllium.

The tirst three tests will be primarily concerned with off-gas release as a function of the abovementioned variables. They will also provide operating experience with the unit betore radionuclides are introduced. The next two tests will concentrate on entrainment and volatility of radionuclides. Tests 6 and 7 will focus on lieding mechunisms and reaction rates for solid-containing components. The tinal test is being considered because beryllium is presently a problem for incinerators due to the toxicity of $\mathrm{BeO}$.

These tests will (1) demonstrate which waste and which conditions allow effective treatments and (2) determine the optimal operating conditions.

\section{SEPARATIONS AND TREATMENTS FOR SPENT SALT}

The salt products irom a molten salt oxidation of mixed wastes will be treated to meet the requirements for one of three dispositions: a recycle of $\mathrm{Na}_{2} \mathrm{CO}_{3}$ (with small amounts of other salts and/or radioactivity) (o) the molten salt oxidation; disposal as a nonradioactive waste; or long-term 
storage as a radioactive waste. All the epent salt could be stabilized in some way and stored as radioactive waste without use of any separation processes (Figure 1). It is probably economically desirable to minimize the storage costs by separating either $\mathrm{Na}_{2} \mathrm{CO}_{3}$ for recycle or a nonradioactive waste salt to give a smaller volume of more concentrated radioactive waste.

The spent salt discharged from an MSO treatment of wastes will have varying compositions of $\mathrm{Na}_{2} \mathrm{CO}_{3}$, other sodium salts, radioactivity, and ash or other solids. The solids removed from the cooled off-gas are likely to be low in $\mathrm{Na}_{2} \mathrm{CO}_{3}$ and high in more volatile compounds such as $\mathrm{NaCl}$, $\mathrm{CsCl}$, or phosphorus oxides. The salt removed to avoid excessive depletion of $\mathrm{Na}_{2} \mathrm{CO}_{3}$ as a chemical reagent is also likely to be low in $\mathrm{Na}_{2} \mathrm{CO}_{3}$. The $\mathrm{Na}_{2} \mathrm{CO}_{3}$ recycle would do little to reduce the total waste volume for these compositions. When salt is replaced to control the physical properties of the melt ( $<20 \mathrm{wt} \%$ solids to prevent excessive viscosities or a limit on $\mathrm{NaCl}$ concentration to limit the vapor pressure), then $\mathrm{Na}_{2} \mathrm{CO}_{3}$ recycle may be important to reduce the volumes of wastes.

An aqueous dissolution of spent salt and separations of the components have been proposed (3), and some experimental results are reported (4). The ash or insoluble metal oxides are filtered from the solution. Evaporation and crystallization at two different temperatures can separate $\mathrm{Na}_{2} \mathrm{CO}_{3}$ (containing some $\mathrm{NaCl} . \mathrm{Na}_{2} \mathrm{SO}_{4}$, and other sodium salts) for recycle and $\mathrm{NaCl}$ for disposal. The radioactive componeits are generally a very small mass fraction of the spent salt. Separation of the insolubles and some ion exchange separations can give a small mass of radioactive waste and much larger amounts of decontaminated waste. The dissolved spent salt is a caustic solution of high sodium concentration. This is chemically very similar to the supernates in miny DOE tank wastes. Therefore, the separation technology developed for removal of radionuclides from these tank supernates should work well for the dissolved spent salts. The recent experimental results for an MSO test with waste oils demonstrated good decontamination of dissolved salts by removal of cesium (4).

A recycle concept proposed tor study at $\mathrm{ORNL}$ is a molten salt extraction of $\mathrm{NaCl}$ and fission products with recycle of the $\mathrm{Na}_{2} \mathrm{CO}_{3}$ and other unextracted components (5). The concept is a solvent extraction separation with two immiscible salts. Selective extractions of actinides and fission products have been reported for some immiscible chloride salts. If laboratory studies can identify an immiscible second salt and significant separation factors for the MSO waste salt components, then a complete separation scheme might be possible. An auxiliary concept is an electrolysis to remove $\mathrm{Cl}_{2}$ and recycle $\mathrm{Na}_{2} \mathrm{O}$ or $\mathrm{Na}_{2} \mathrm{CO}_{3}$ to the MSO process. 
Concepts for stabilization of spent salts for storage have been proposed. Formation of glasses and leach tests were reported for 10 to $40 \mathrm{wt} \%$ salts $\left(\mathrm{NaCl}\right.$ and $\left.\mathrm{Na}_{2} \mathrm{SO}_{4}\right)$ (2). Cementation of 10 to $40 \mathrm{wt} \%$ salts $\left(\mathrm{Na}_{2} \mathrm{CO}_{3}-\mathrm{Na}_{2} \mathrm{SO}_{4}-\mathrm{NaCl}\right)$ gave cements with leach rates about 10 times greater than the glasses. These old results could not meet the current waste leach specifications, but the technology for both glasses and cementation has been greatly improved.

\section{BIBLIOGRAPHY/REFERENCES}

1. S. J. Yosim et al., in Safe Handling of Chemical Carcinogens, Mutagens, Teratogens, and Highly Toxic Substances, Vol. 2. D. B. Waters, Ed., Ann Arbor Scicnce, Ann Arbor, MI, 1979, p. 617.

2. S. J. Yosim et al., in Toxic and Hazardous Waste Disposal, Vol. 4, R. B. Pojasek, Ed., Ann Arbor Science, Ann Arbor, MI, 1980, p. 227.

3. D. E. McKenzie et al., in $A I C h E$ Sym. Ser., Vol. 72, R. E. Tomlison, Ed., American Institute of Chem. Engr., New York, 1s?6, p. 69.

4. J. D. Navratil et al., in Emerging Technologies in Hazardous Waste Management, An American Chemical Society Symposium, Atlanta, GA. September 17-29, 1993, p. 463.

5. L. M. Toth, Oak Ridge National Laboratory, personal communication, September 1993. 
ORNL DWG 93A-754

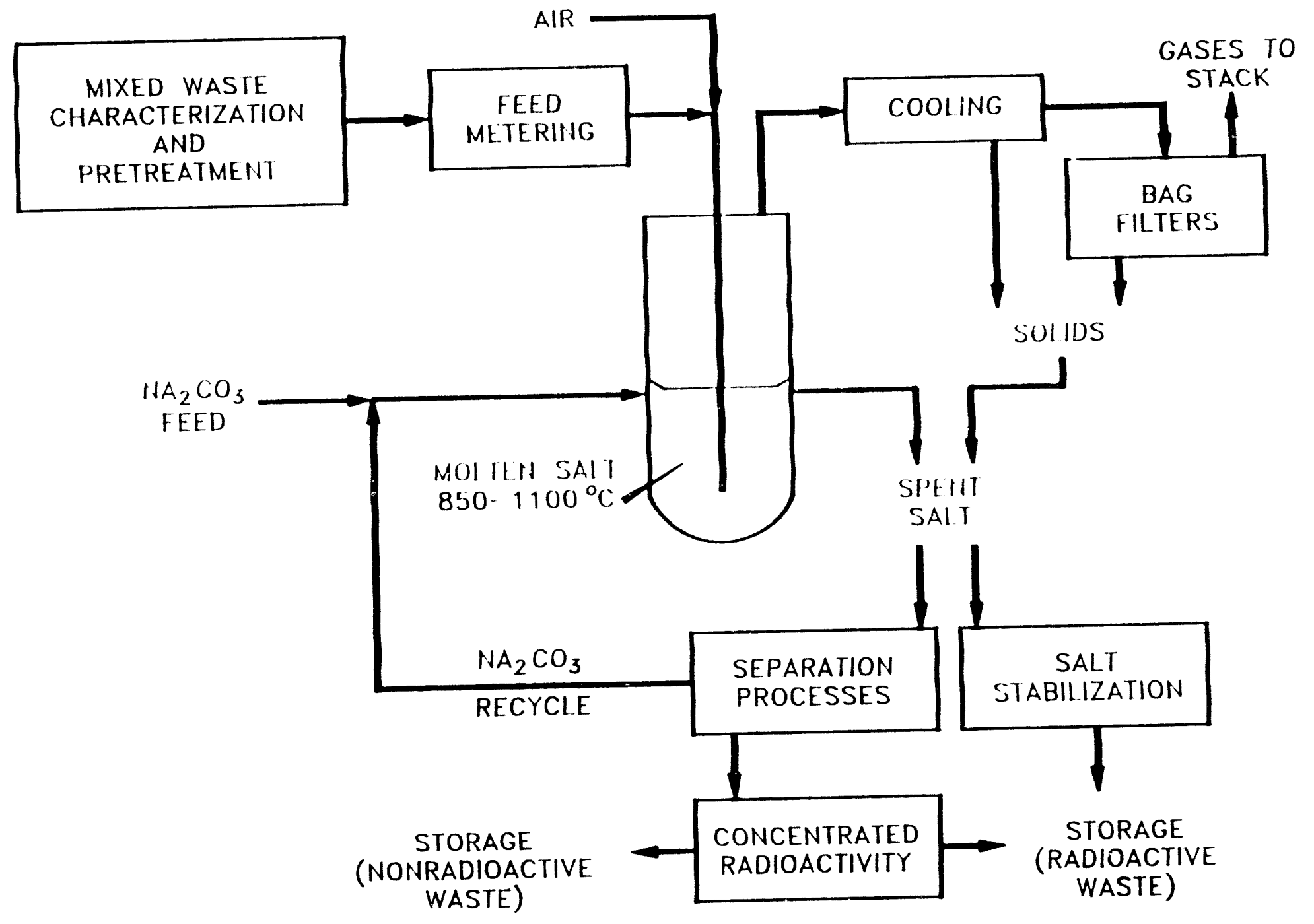

Fig. 1. Molten salt oxidation of mixed wastes and treatment of residues. 


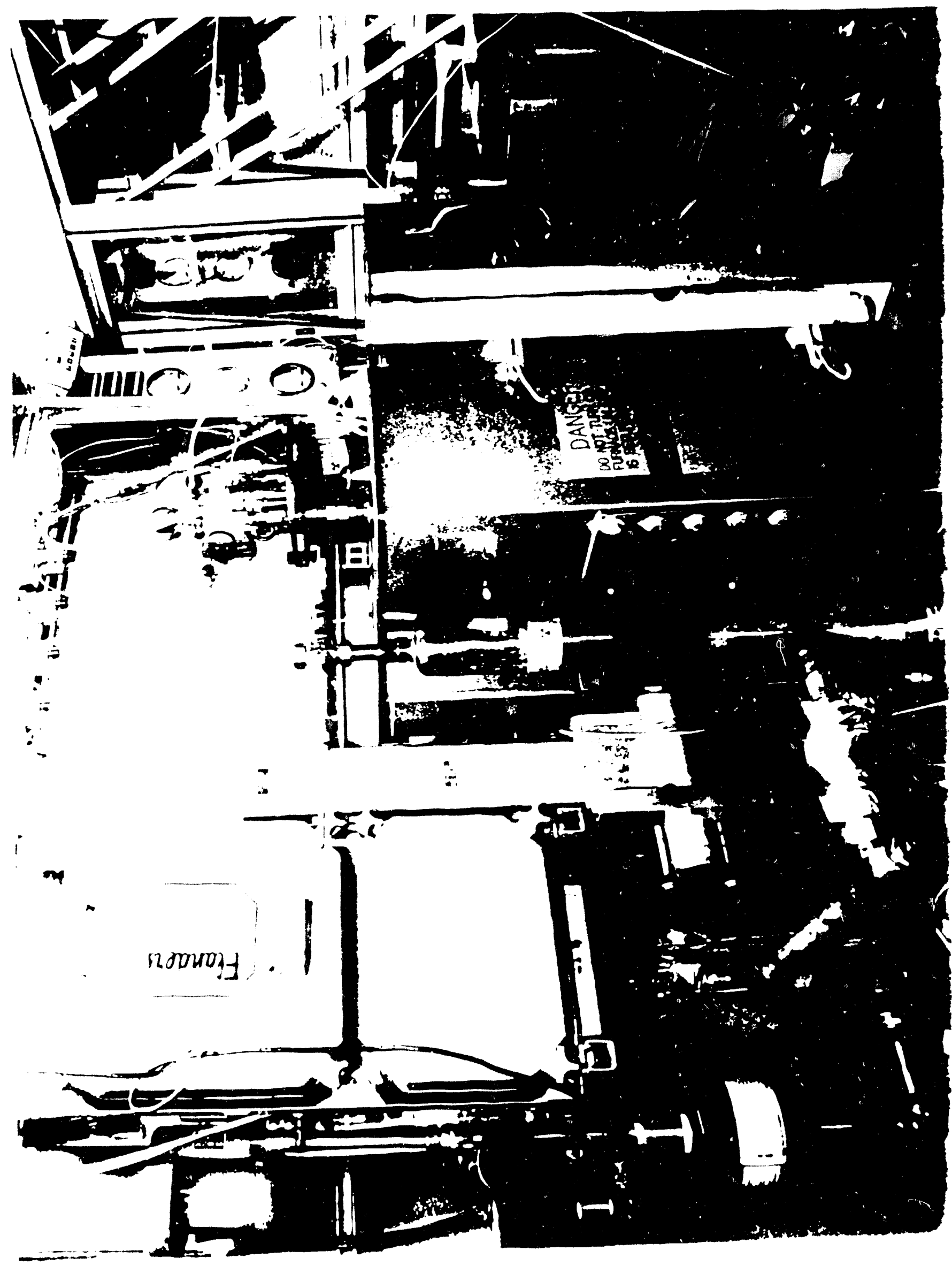



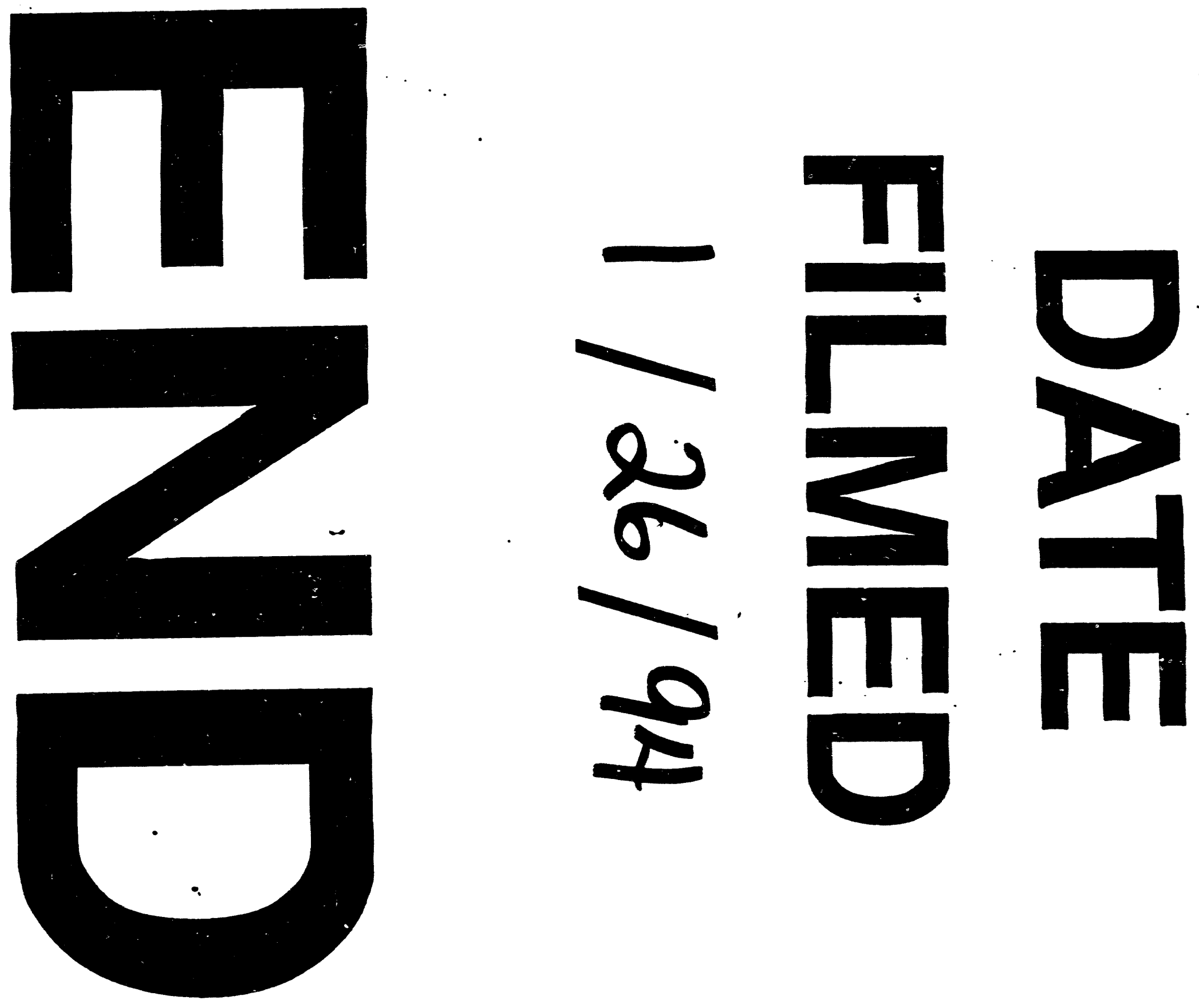